\title{
Investigation of Airborne Particulate Matter in the Atmosphere of the Black Sea Coastal Zone Based on the Measured and Satellite Data
}

\author{
A. V. Varenik ${ }^{凶}$, D. V. Kalinskaya, M. A. Myslina \\ Marine Hydrophysical Institute of RAS, Sevastopol, Russian Federation \\ 凶alla.varenik@mhi-ras.ru
}

\begin{abstract}
Purpose. One of the most pressing problems of large cities is air pollution resulting from presence of various large and fine particles in the air. These micro-particles can be transported by the air currents over considerable distances, as well as coagulate various substances also present in the atmosphere. The purpose of the work is to study the content of particulate matter of 2.5 and 10 microns (PM2.5 and PM10) in the atmosphere of Sevastopol, as well as the processes affecting their concentration. Methods and Results. During the period from February to June, 2020, the scientists of Marine Hydrophysical Institute (MHI), RAS measured mass concentration of PM2.5 and PM10 in Sevastopol using the "Atmas" dust analyzer. A total of 180 measurements of the micro-particle concentrations in the air of Sevastopol were done, and 60 values of the PM2.5 and PM10 daily average concentrations were obtained. To analyze the preferred aerosol type for the dates with high content of suspended particles in the air, the CALIPSO satellite data were used. It is shown that the smoke recorded in the Sevastopol atmosphere on 19.02.2020 could lead to increase of the PM10 particles concentration. A day before the increased concentrations of suspended particles were revealed in the Sevastopol atmospheric air, the CALYPSO satellite data on aerosol typing over the Black Sea had shown predominance of the smoke aerosol in the atmosphere over the region under study.

Conclusions. The results of the investigation shows that in the atmosphere of Sevastopol, the cases when the PM2.5 and PM10 particles contents exceeded the maximum permissible daily average concentration by up to 3.4 times were detected. It was found that the main cause of air pollution with micro-particles in Sevastopol was the transfer both of air masses from the deserts in the African continent and Asia and the burning biomass aerosol (smoke). Air pollution with the PM10 particles caused by the local source, namely soil excavation in immediate proximity to the air sampling point, was less significant.
\end{abstract}

Key words: atmosphere, micro-particles, $P M 10, P M 2.5$, 24-hour average limit concentration

Acknowledgements: the investigation was carried out within the framework of the state task on themes No. 0555-2021-0003 and No. 0555-2021-0005, and the RFBR projects No. 19-05-50023 Mikromir and No. 18-05-80028.

For citation: Varenik, A.V., Kalinskaya, D.V. and Myslina, M.A., 2021. Investigation of Airborne Particulate Matter in the Atmosphere of the Black Sea Coastal Zone Based on the Measured and Satellite Data. Physical Oceanography, [e-journal] 28(3), pp. 326-337. doi:10.22449/1573-160X2021-3-326-337

DOI: $10.22449 / 1573-160 X-2021-3-326-337$

(C) A. V. Varenik, D. V. Kalinskaya, M. A. Myslina, 2021

(C) Physical Oceanography, 2021

\section{Introduction}

Particulate matter (PM) is a widespread atmospheric pollutant. Its concentration has significantly increased recently [1, 2]. Particulate atmospheric matter is a mixture of organic and inorganic substances with a wide spatiotemporal variability of physical and chemical characteristics [3]. Its most common chemical components include sulfates, nitrates, ammonia and other inorganic ions (sodium, potassium, calcium, magnesium and chloride ions, organic and elemental carbon, crustal minerals, particle-bound water, metals and polycyclic aromatic 
hydrocarbons. Biological components, such as allergens and microorganisms, can also be found in PM. Microparticles can be of natural (dust transfer, soil erosion) and anthropogenic origin (soot, dust, micro-fragments of asphalt and rubber, mineral salts (sulfates, nitrates) and heavy metal compounds) [4-8].

Operation of internal combustion engines, the combustion of various types of fuel (coal, brown coal, heavy oil and biomass) in boiler houses, construction, many types of production (especially the production of cement, ceramics, bricks and smelting production), transshipment of bulk cargo (for example, grain) are the main sources of particulate matter entry to the urban atmosphere [3]. The most important feature of air pollution in modern cities is the almost complete domination of emissions from vehicles and power plants. Under unfavorable meteorological conditions (calm, fog, trapping layers and high air temperature), contributing to the accumulation of harmful impurities, the concentration of harmful substances can increase by $2-3$ times $[9,10]$. PM content variability in the ambient air can also be seasonal and diurnal [11].

The indicators that are most often used to characterize PM are mass concentrations of particles with a diameter of less than $10 \mu \mathrm{m}$ (PM10) and less than $2.5 \mu \mathrm{m}$ (PM2.5) [1, 2]. For comparison, a human hair is about 100 microns in diameter.

PM2.5 is often referred to as fine particulate matter, also including ultrafine particles less than 0.1 microns in diameter. In most part of Europe, PM2.5 accounts for $50-70 \%$ of the total PM10 volume [3]. PM with a diameter of $0.1 \mu \mathrm{m}$ to $1 \mu \mathrm{m}$ can remain in ambient air for many days and weeks and, accordingly, be subject to long-range transboundary transport.

The amount of microparticles (PM2.5 and PM10) in the atmosphere and their characteristics can be an important indicator of the ecological state of the natural environment when exposed to human activities. Air quality in cities is currently one of the most pressing environmental problems. Air pollution reaches critical levels in most cities around the world. According to WHO estimates, air quality indicators in the 20 largest cities in the world are several times higher than the standards established by this organization. In the Russian Federation, about half of the country's population lives in cities with the norms of ambient air pollution being exceeded [12].

Directive 2008/50/EC of the European Parliament and of Council of 21 May 2008 on ambient air quality and cleaner air for Europe ${ }^{1}$ was adopted. It includes the values of the limit levels (concentrations) of pollutants, as well as PM10 and PM2.5, aimed to prevent or reduce the negative impact on human health and (or) on the environmental state as a whole.

The mass PM2.5 concentration is a key parameter for estimating air quality and air pollution effects on human health. According to WHO standards ${ }^{2}$, the mean annual PM2.5 level should be no more than $0.01 \mathrm{mg} / \mathrm{m}^{3}$, and the mean diurnal level should not exceed $0.025 \mathrm{mg} / \mathrm{m}^{3}$. The PM10 content in the atmosphere of cities

\footnotetext{
${ }^{1}$ Directive 2008/50/EC of the European Parliament and of Council of 21 May 2008 on ambient air quality and cleaner air for Europe. Official Journal of the European Union, 11.6.2008, L 152/1, 51, pp. 1-44. Available at: https://eur-lex.europa.eu/eli/dir/2008/50/oj [Accessed: 10 May 2021].

${ }^{2}$ European Evironment Agency. Air Quality Standards under the Air Quality Directive, and WHO Air Quality Guidelines. (2021). [online] Available at: https://www.eea.europa.eu/themes/dataand-maps/figures/air-quality-standards-under-the [Accessed: 10 May 2021].
} 
should not be more than: the mean annual $-0.025 \mathrm{mg} / \mathrm{m}^{3}$ and the average daily $0.050 \mathrm{mg} / \mathrm{m}^{3}$. In 2021 the Russian Federation adopted softer regulatory values in comparison with the EU Directive: the maximum permissible annual concentration of PM10 is 0.040 , PM2.5 is $0.025 \mathrm{mg} / \mathrm{m}^{3}$; the mean diurnal $-0.060 \mathrm{mg} / \mathrm{m}^{3}$ and $0.035 \mathrm{mg} / \mathrm{m}^{3}$ respectively (SanPiN 1.2.3685-21). In accordance with the normative document $^{3}$, one-time concentrations are also standardized. Maximum single particle concentrations are $0.300 \mathrm{mg} / \mathrm{m}^{3}$ (PM10) and $0.160 \mathrm{mg} / \mathrm{m}^{3}$ (PM2.5).

At the same time, regular monitoring of airborne dust content is carried out only in large cities and on the territory of reserves [13]. A relatively accurate estimate of PM10 is possible only in three large cities - Moscow, St. Petersburg and Krasnoyarsk, where the constant monitoring of these particles in the ambient air is carried out by city and regional environmental organizations [2]. Compared to other countries, the observation network in Russia is underdeveloped and informative ${ }^{4}$.

In 2016, WHO published a report on the PM10 and PM2.5 content in the ambient air of 2,975 cities around the world ${ }^{5}$. This report indicates that the ambient air quality depends to a certain extent on the socio-economic state of the country. Particulate matter concentrations are higher in cities in Asian countries (India, Pakistan, Afghanistan, China and Mongolia) and the Eastern Mediterranean. However, the report did not consider such significant factors as the proximity of cities to arid areas and traffic load. Droughts and intensive exploitation of pastures lead to a reduction in vegetation cover in large areas of arid zones in Asia and Africa and the removal of dust particles from them [2]. As a result of sand and dust storms, dust can rise high into the atmosphere and be carried over long distances, often moving across the oceans [14-17]. Each year, such storms carry into the oceans an average of half a billion tons of minerals and nutrients, which, coming from the atmosphere, can affect the primary production of the ocean, including its coastal regions. This process triggers biogeochemical cycles in the oceans, including the cycle of carbon, nitrogen, sulfur, phosphorus and silicon ${ }^{6}$.

Sevastopol is a city located on the Black Sea coast. As of January 1, 2020, according to the data of the Office of the Federal State Statistics Service for the Republic of Crimea and the city of Sevastopol (Krymstat), its population was about 500,000 people; by mid-March 2020, according to the Government of Sevastopol, there were more than 700,000. Activity of enterprises, the basing of the Black Sea Fleet, as well as the operation of various types of transport (land, water and air) have a significant impact on the air pollution level of the city.

\footnotetext{
${ }^{3}$ Chief State Sanitary Doctor of the Russian Federation, 2021. On the Approval of Sanitary Rules and Norms SanPiN 1.2.3685-21 "Hygienic Standards and Requirements for Ensuring the Safety and/or Harmlessness of Environmental Factors for Humans": Resolution No. 2. Available at: https://docs.cntd.ru/document/573500115 [Accessed: 10 May 2021] (in Russian).

${ }^{4}$ World Air Quality Index project team. Beijing Air Pollution: Real-time Air Quality Index (AQI). 2021. [online] Available at: http://aqicn.org/city/beijing/ [Accessed: 10 May 2021].

${ }^{5}$ WHO, 2013. Health Effects of Particulate Matter : Policy Implications for Countries in Eastern Europe, Caucasus and Central Asia. Available at: https://www.euro.who.int/_data/assets/pdf_file/0006/189051/Health-effects-of-particulate-matter-finalEng.pdf [Accessed: 10 May 2021].

${ }^{6}$ UNEP, 2020. Impacts of Sand and Dust Storms on Oceans: A Scientific Environmental Assessment for Policy Makers: report. Available at: https://www.unep.org/resources/report/impacts-sand-and-duststorms-oceans [Accessed: 10 May 2021].
} 
In Sevastopol, works on measuring the particle size distribution of the atmosphere was carried out by employees of the Sevastopol branch of the SOI in 2015-2016. According to the published data, the highest values of the PM2.5 concentration in the ambient air were observed with winds from the eastern points, which indicates a terrigenous source of their entry. Excess of the 24-hour average limit values PM10 and PM2.5 was observed near the road [18, 19].

The present paper is aimed to study the PM2.5 and PM10 content in the atmosphere of Sevastopol, as well as the processes affecting their concentration.

\section{Materials and Methods}

From mid-February to the end of June 2020, the mass PM2.5 and PM10 concentration was measured using the Atmas dust analyzer (produced in Russia).

The instrument operation principle is based on the charge of dust particles in the corona discharge field, created by a high-voltage electrode and their subsequent deposition on the dust sensor surface, used as a quartz piezoelectric element. The dust meter directly measures the mass concentration. The analyzer allows measurements in various modes (for example, express measurements (30 s)) or select the exposure time. Measurement range of the mass concentration of dust is $0.1-150 \mathrm{mg} / \mathrm{m}^{3}$. The permissible error limit in the concentration range from 0.1 to $20 \mathrm{mg} / \mathrm{m}^{3}$ is equal to $\pm 20 \%$. If the dust concentration in the air is more than $20 \mathrm{mg} / \mathrm{m}^{3}$, it is necessary to use a special diluent cartridge, thereat the error is \pm 25\% (URL: https://ntm.ru/products/150/8342).

Concentrations of microparticles in the ambient air of Sevastopol were measured three times a day; the duration of exposure and the averaging period of PM2.5 and PM10 concentrations were 20 min. Every 5 seconds, single values of the concentration of microparticles were recorded.

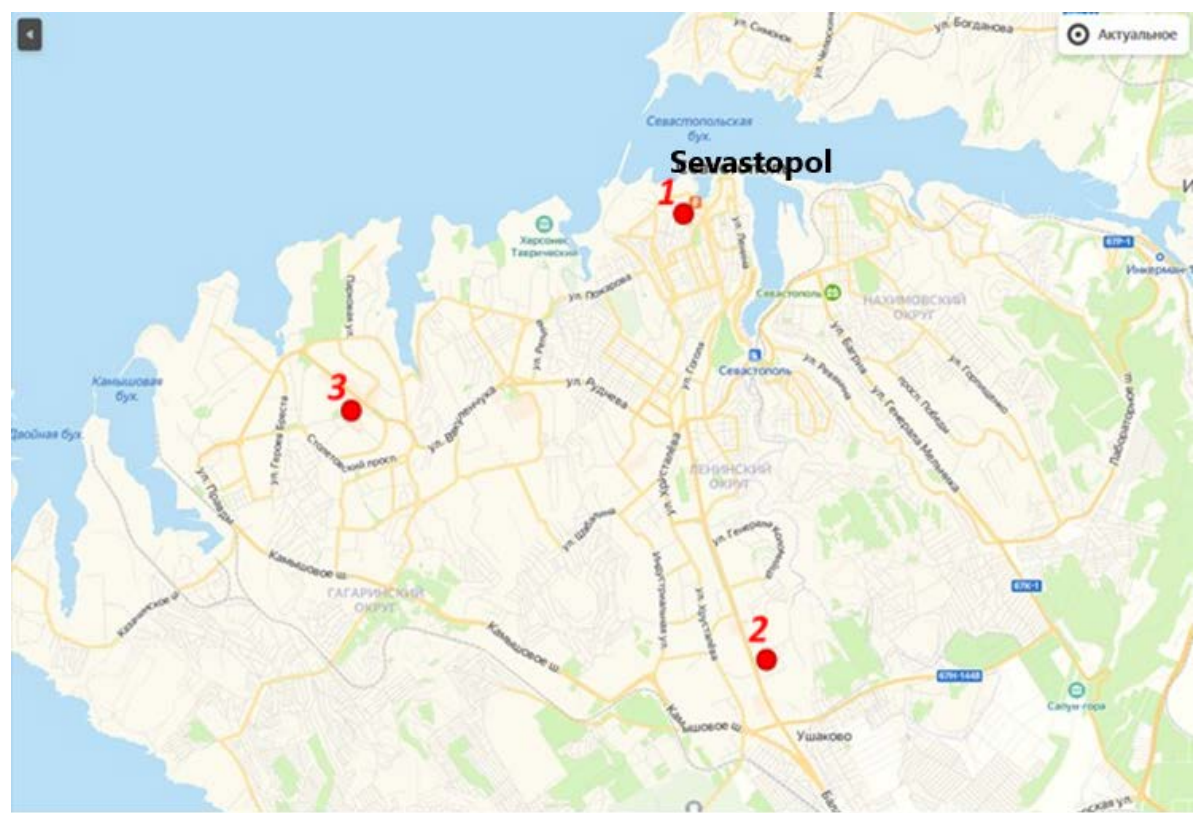

F i g. 1. Scheme of ambient air sampling points: 1 - at the roof of Marine Hydrophysical Institute, 2 - in Ostryakova Avenue, 3 - in Oktyabr'skoi Revolyutsii Avenue 
The main point of air sampling was at Marine Hydrophysical Institute (MHI) in Sevastopol (Fig. 1) at an altitude of $40 \mathrm{~m}$ above the underlying surface. MHI is surrounded by the Sevastopol Bay on both sides. As a result, this point can be used as a reference one for detecting cases of microparticles entering the atmosphere both from a local source and as a result of their transboundary transfer.

Measurements were also carried out in two other points of the city - in the area of Generala Ostryakova Avenue, as well as of Oktyabr'skoi Revolyutsii Avenue (Fig. 1). Both of these streets are characterized by significant car traffic, but during the quarantine period the traffic was not so intense, which made it possible to avoid additional air pollution. The air sampling point on Oktyabr'skoi Revolyutsii Avenue was $35 \mathrm{~m}$ above the underlying surface, which corresponded to the height of the sampling point in MHI. Ambient air samples at a point on Ostryakova Avenue were taken at $10 \mathrm{~m}$ height.

For a more complete interpretation of the data obtained, it is advisable to use information coming from optical instruments such as MODIS, CALIPSO, etc. [20]. In the present work, to analyze the predominant type of aerosol on days with an increased PM content in the air, the CALIPSO satellite data was analyzed. The principal purpose of CALIPSO is to carry out global measurements of aerosols and clouds. Such measurements are needed for a better understanding of the impact of aerosols and clouds on the climate system, as well as for improvement of the ability to predict long-term, seasonal and interannual climate changes. CALIPSO is paired with the US CloudSat (Cloud Satellite) system, a $94 \mathrm{GHz}$ nadir-directed radar that measures energy backscattered from clouds as a function of distance. In CALIPSO, the type of aerosols is determined based on identification by the AERONET cluster analysis method: smoke (burned biomass), dust, contaminated dust (mixtures of dust and smoke), contaminated continental and pure continental aerosol [21, 22].

\section{Results and Discussion}

In total, 180 measurements of the microparticles' concentration in the air of Sevastopol were carried out, 60 values of the mean diurnal PM2.5 and PM10 concentration were obtained. Average concentrations of microparticles in the atmosphere at the sampling points for the period under study are presented in the table.

\section{Average PM10 and PM2.5 concentrations in the ambient air of Sevastopol}

\begin{tabular}{l|c|c}
\hline Point of air sampling & PM2.5, $\mathrm{mg} / \mathrm{m}^{3}$ & $\mathrm{PM} 10, \mathrm{mg} / \mathrm{m}^{3}$ \\
\hline MHI & 0.016 & 0.024 \\
Oktyabr'skoi Revolyutsii Avenue & 0.016 & 0.024 \\
Ostryakova Avenue & 0.016 & 0.030 \\
\hline
\end{tabular}


During the measurements, the maximum one-time concentration of PM10 and PM2.5 particles (the concentration obtained during sampling for $20 \mathrm{~min}$ ) did not exceed the established limit values. At the same time, the mean diurnal PM10 and PM2.5 concentration exceeded the maximum permissible one only in single cases. For example, on February 19, 2020, the PM10 concentration was $0.104 \mathrm{mg} / \mathrm{m}^{3}$, on March 26, $2020-0.202 \mathrm{mg} / \mathrm{m}^{3}$, which is 1.7 and 3.4 times, respectively, higher than the 24-hour average limit concentration.

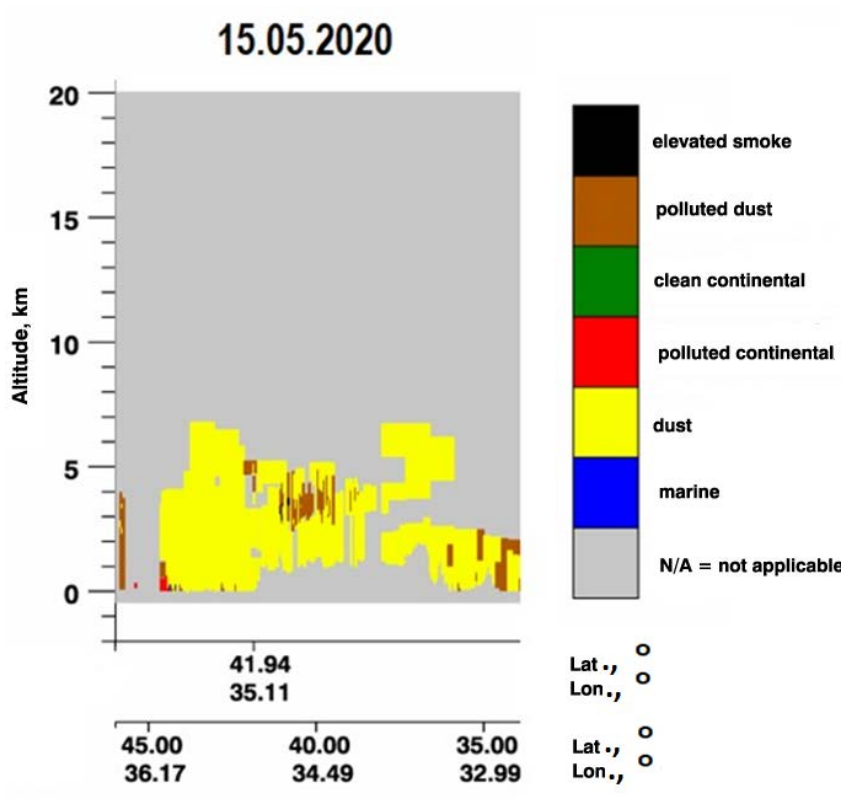

F i g. 2. CALIPSO satellite data on the aerosol typing over the Black Sea for February 18, 2020
When analyzing the CALIPSO satellite data for 2020, obtained on days with increased PM concentrations, it was revealed that on February 19, 2020, smoke was recorded in the atmosphere of Sevastopol, which could lead to an increase in the PM10 concentration. The CALIPSO satellite data on the aerosol typing over the Black Sea a day before the detection of increased PM concentrations in the ambient air of Sevastopol showed the prevalence of smoke in the atmosphere over the region under study (Fig. 2).

According to the Ventusky application (URL: https://www.ventusky.com), the intense source of PM10 transport for 19.02.2020 was in Azerbaijan (the Caspian Sea region), which is confirmed by 7-day back-trajectories according to the AERONET data (transport at three heights from the east). The MODIS satellite data on thermal anomalies in the Black Sea region did not reveal an intense source of smoke. Thus, the transfer of this aerosol type from the territories more distant from the considered region is confirmed.

When analyzing the data on the trajectories of air masses for March 26, 2020, an intense transport of dust aerosol from the Kaplankyr reserve (Turkmenistan) was revealed (Fig. 3). 


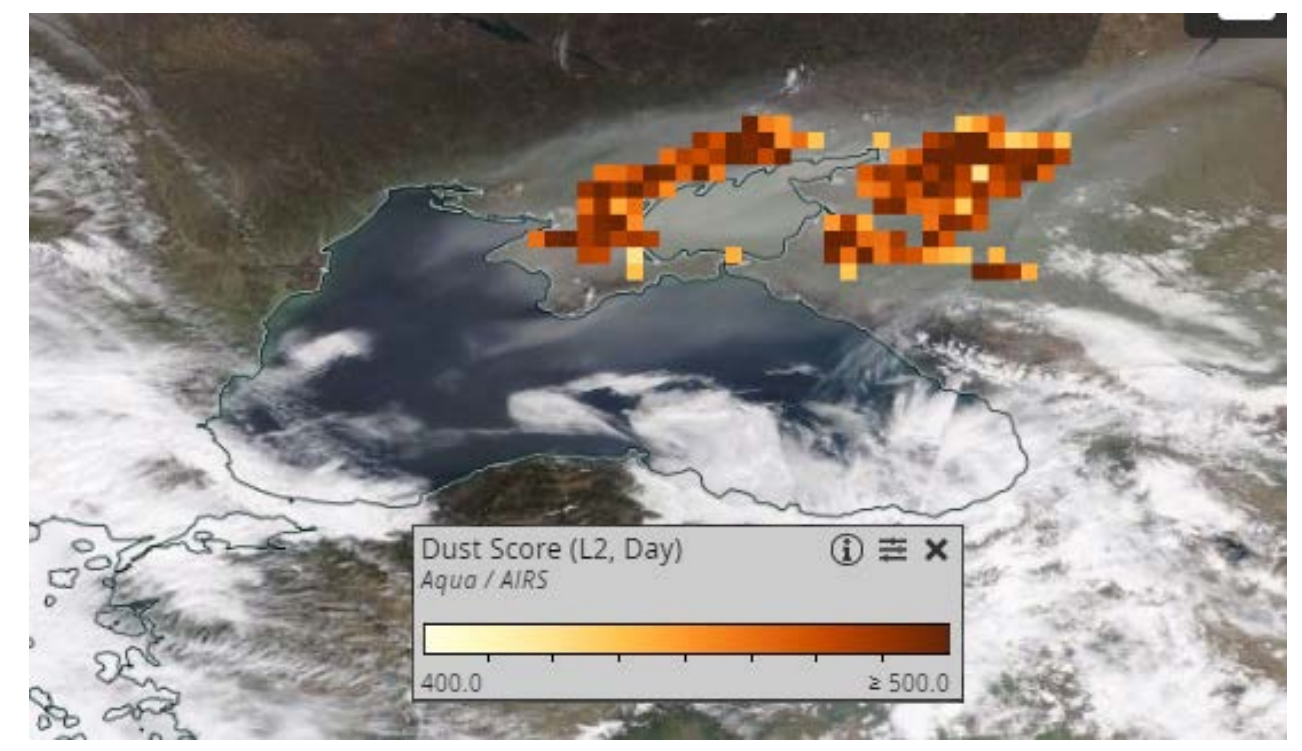

F i g. 3. Dust aerosol transport over the Black Sea region according to the MODIS satellite data

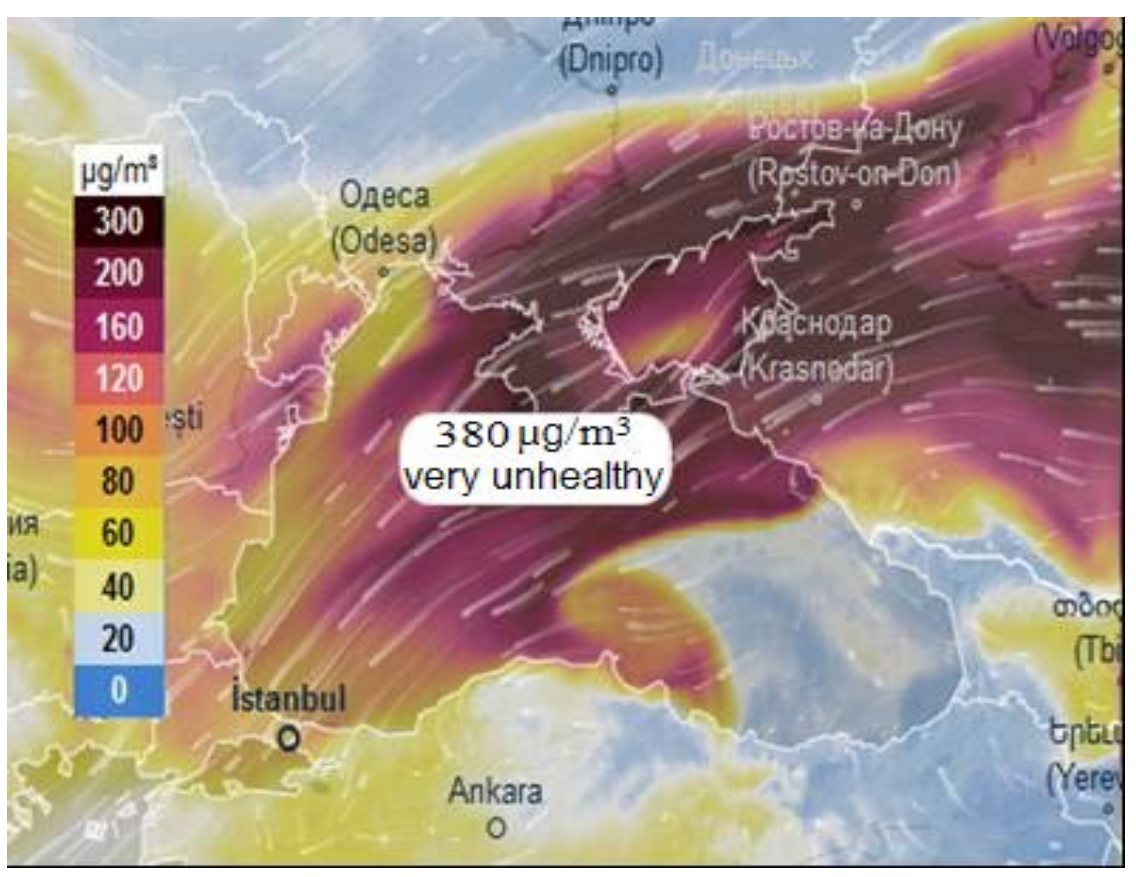

F i g. 4. Dust aerosol transport over the Black Sea region according to the Ventusky data for March 26, $2020 \mu$

PM10 particle concentrations were also analyzed using the Ventusky data. The main weather data providers for the Ventusky app are DWD and NOAA. In accordance with Fig. 4, on March 26, 2020, an abnormally high concentration of PM10 particles was recorded in the ambient air of Sevastopol, which were transported by the surface wind of an eastern direction. 
This transfer, most likely, became the reason for the Sevastopol air saturation with dust particles $10 \mu \mathrm{m}$ sized.

In some cases, as a result of the measurement, it was found that the mean diurnal concentration of microparticles didn't exceed the 24-hour average limit concentration so significantly - the PM2.5 concentration reached $0.048 \mathrm{mg} / \mathrm{m}^{3}$, and PM10 - $0.094 \mathrm{mg} / \mathrm{m}^{3}$ (which is 1.5 and 1.6 times higher than the limit values, respectively).

The certified lower limit of measurement of the analyzer used for these particles is $0.1 \mathrm{mg} / \mathrm{m}^{3}$. However, the verification certificate indicates that the verification was carried out in the full range using the state working standard of the mass concentration of particles in the range of values from 0.01 to $10000 \mathrm{mg} / \mathrm{m}^{3}$. Hence, the obtained concentration values can serve as an indicator characteristic of ambient air pollution with PM.

This data shows that with a certain character of meteorological parameter variability, favorable conditions for increasing the concentration of the studied particles of atmospheric aerosol are formed. Almost all cases of an increase in the PM2.5 and PM10 concentrations were detected with a wind speed of 4-7 m/s.

18.02.2020

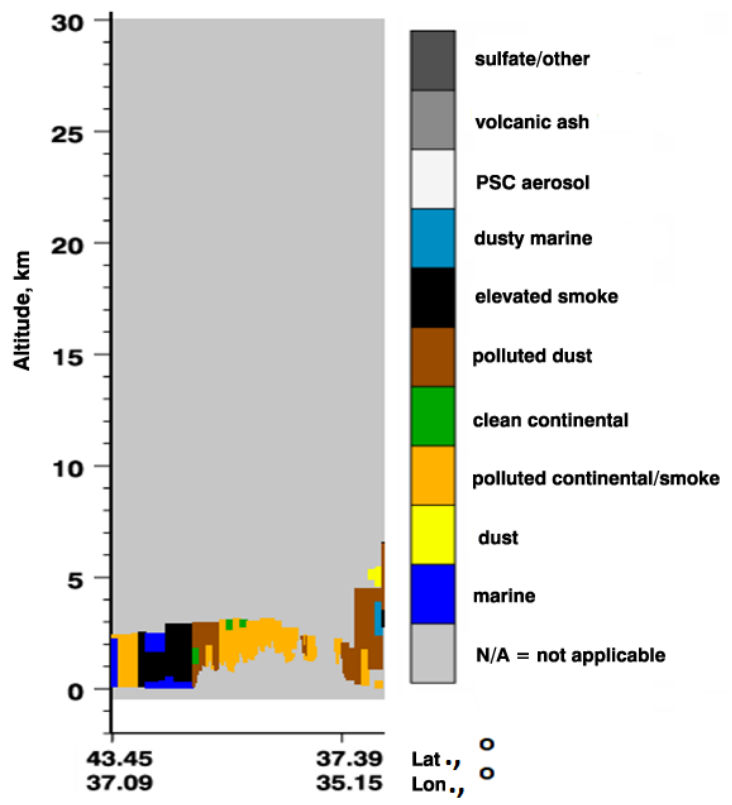

To determine the sources of atmospheric aerosol, the 7-day back-trajectories of air mass were analyzed according to the AERONET and HYSPLIT data. It was found that the dates when the increased PM concentrations in the air were recorded coincide with the periods of dust aerosol transport from the African and Asian deserts towards the Black Sea region. For example, on May 15, 2020 (Fig. 5), May 28, 2020, and from June 4 to June 5, 2020, dust transport was determined, while the mean diurnal PM2.5 concentrations were $0.037-0.048 \mathrm{mg} / \mathrm{m}^{3}$ and PM10 - 0.069-0.094 mg/m³.

F i g. 5. CALIPSO satellite data on the aerosol typing over the Black Sea for May 15, 2020

Increased PM10 concentrations were also noted on February 27, 2020, the mean diurnal concentration was $0.075 \mathrm{mg} / \mathrm{m}^{3}$, which 1.25 times exceeds the 24-hour average limit concentration. On this day the southwestern wind of $5 \mathrm{~m} / \mathrm{s}$ prevailed. Wind direction indicates a possible source of dust the construction site near MHI associated with soil extraction (Fig. 6), which could lead to the PM10 level increase in the atmosphere. 


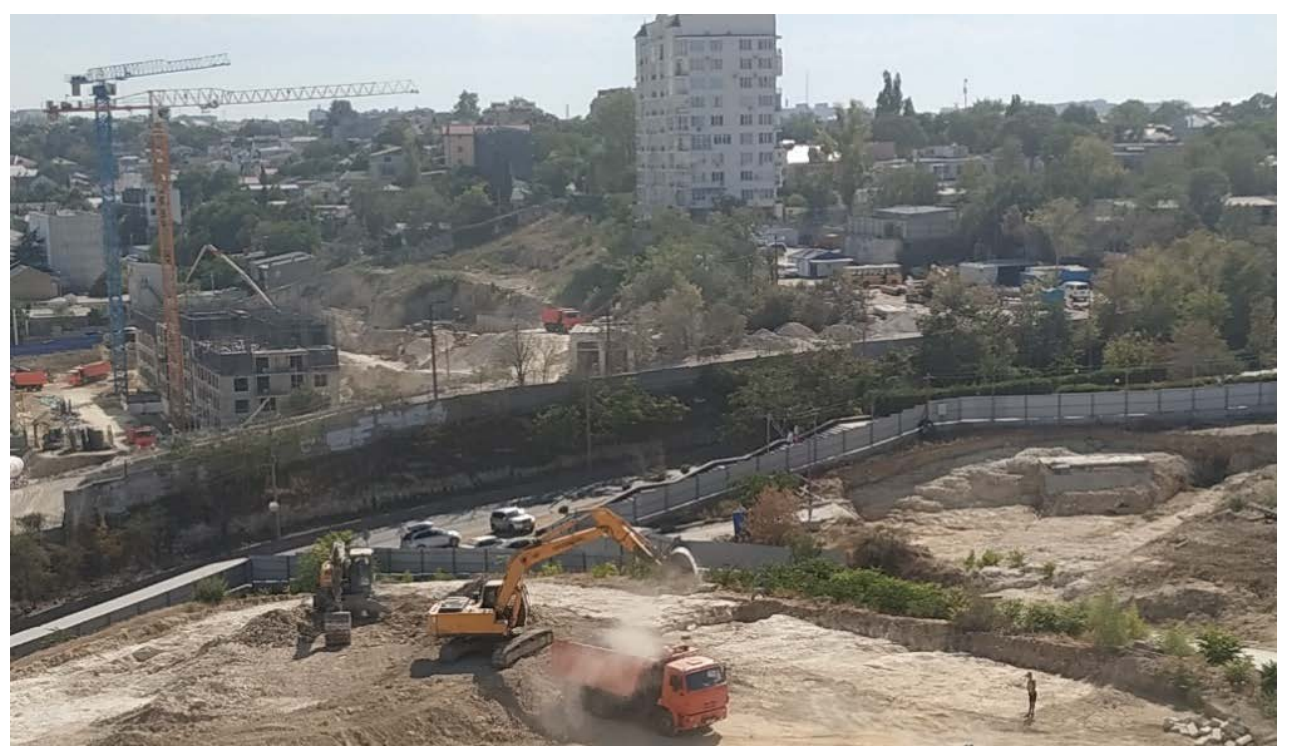

F i g. 6. Construction site near Marine Hydrophysical Institute

According to the analysis of the 7-day back-trajectories of air mass, no dust outflows were recorded either from the Sahara Desert or from Asia on this and several previous days. This confirms the local origin of air pollution source at the sampling point.

On the preceding and following days, the wind during sampling predominantly was of the western or eastern direction with a speed of $2-3 \mathrm{~m} / \mathrm{s}$. As a result, microparticles entering the ambient air from the construction site did not reach the sampling point. PM10 concentrations on these days averaged $0.01-0.03 \mathrm{mg} / \mathrm{m}^{3}$. It can be concluded that the impact of a local source of atmospheric air pollution largely depends on local meteorological conditions, namely, on the wind direction.

It should be noted that in the case of atmospheric precipitation on days with high PM concentrations in the air, an increased content of nutrients (inorganic nitrogen, phosphates and silicon) was determined. A significant excess of the background concentrations of these nutrients was also observed in the surface layer of the Sevastopol Bay. This situation under certain conditions (for example, in the case of stable summer stratification) can lead to outbreaks of phytoplankton blooms and a possible decrease in the oxygen content in seawater.

\section{Conclusions}

During February - June 2020, the PM2.5 and PM10 content in the atmosphere of Sevastopol was analyzed. Features of the air pollution variability with PM10 and PM2.5, due to both long-range transport of air masses and local meteorological conditions, were revealed.

As a result, the dates when the mass PM10 concentration exceeded the maximum permissible concentration more than three times were determined. 
During comprehensive analysis of the data obtained, it was revealed that most cases of exceeding the 24-hour average limit concentrations are due to the longdistance transport of air masses from the African and Asian deserts, as well as the transport of smoke.

At the same time, cases of less significant PM10 and PM2.5 concentrations, caused by local sources of dustiness in the atmosphere, were identified. The wind direction on these days indicates a possible source of dust - ground works in the immediate vicinity of MHI. When the wind direction changed to the west or east, the concentration of microparticles in the ambient air in the sampling area decreased. It is assumed that the intensity and duration of the impact of a local source of atmospheric air pollution is largely determined by meteorological conditions at the sampling point, mainly by the wind speed and direction.

The research results are preliminary, and work in this field is planned to be continued in the future.

\section{REFERENCES}

1. Makosko, A.A. and Matesheva, A.V., 2020. Atmospheric Pollution of Population Life Quality in the 21st Century: Threats and Prospects. Moscow: Russian Academy of Sciences, 258 p. (in Russian).

2. Revich, B.A., 2018. Fine Suspended Particulates in Ambient Air and Their Health Effects in Megalopolises. Problems of Ecological Monitoring and Ecosystem Modelling, 29(3), pp. 5378. https://doi.org/10.21513/0207-2564-2018-3-53-78 (in Russian).

3. Kalaeva, S.Z., Muratova, K.M., Chitiykov, Y.V. and Chebotarev, P.V., 2016. Influencing Fine-Dispersed Dust upon Biosphere and Human. Izvestiya Tula State University, (3), pp. 4063 (in Russian).

4. Lisitzin, A.P., 2013. Oceanic Sedimentation: Lithology and Geochemistry. Hoboken, NJ, USA: John Wiley \& Sons, Inc., 407 p.

5. Golokhvast, K.S., Aleinikova, E.A., Nikiforov, P.A., Gulkov, A.N. and Khristoforova, N.K., 2012. Size Analysis of Suspended Micro Particles in Rainfalls of Khabarovsk City. Water: Chemistry and Ecology, (6), pp. 117-122 (in Russian).

6. Simonova, I.N. and Antonyuk, M.V., 2015. The Role of Industrial Air Pollution in Growth of Bronchopulmonary Pathology. Health. Medical Ecology. Science, (1), pp. 14-20. Available at: https://yadi.sk/i/KGO65DKmciVGN [Accessed: 08 May 2021] (in Russian).

7. Brines, M., Dall'Osto, M., Beddows, D.C.S., Harrison, R.M., Gómez-Moreno, F., Núñez, L., Artíñano, B., Costabile, F., Gobbi, G.P., Salimi, F., Morawska, L., Sioutas, C. and Querol, X., 2015. Traffic and Nucleation Events as Main Sources of Ultrafine Particles in High-Insolation Developed World Cities. Atmospheric Chemistry and Physics, 15(10), pp. 5929-5945. https://doi.org/10.5194/acp-15-5929-2015

8. Vu, T.V., Delgado-Saborit, J.M. and Harrison, R.M., 2015. Review: Particle Number Size Distributions from Seven Major Sources and Implications for Source Apportionment Studies. Atmospheric Environment, 122, pp. 114-132. https://doi.org/10.1016/j.atmosenv.2015.09.027

9. Garger, E.K., 1986. [On the Estimation of the Velocity and Direction of Impurity Transport in the Boundary Layer of the Atmosphere]. In: IEM, 1986. Proceedings of the Institute of Experimental Meteorology. Moscow: MO Gidrometeoizdata. Issue 37, pp. 55-65 (in Russian). 
10. Wang, W., 2016. Progress in the Impact of Polluted Meteorological Conditions on the Incidence of Asthma. Journal of Thoracic Disease, 8(1), E57-E61. doi:10.3978/j.issn.20721439.2015.12.64

11. Kuznetsova, I.N., Glazkova, A.A., Shalygina, I.Yu., Nakhaev, M.I., Arkhangelskaya, A.A., Zvyagintsev, A.M., Semutnikova, E.G., Zakharova, P.V. and Lezina, E.A., 2014. Seasonal and Diurnal Variability of Particulate Matter $P M_{10}$ in Surface air of Moscow Habitable Districts. Optika Atmosfery i Okeana, 27(6), pp. 473-482 (in Russian).

12. Malyshev, V.P., 2006. Major Threats and Hazards Facing the Population of Large Cities. Issues of Risk Analysis, 3(4), pp. 338-345 (in Russian).

13. Kholodov, A., Ugay, S., Drozd, V., Maiss, N. and Golokhvast, K., 2017. Data on Microscale Atmospheric Pollution of Bolshoy Kamen Town (Primorsky Region, Russia). IOP Conference Series: Earth and Environmental Science, 90, 012023. doi:10.1088/17551315/90/1/012023

14. Adushkin, V.V., Chen, B.B., Popel, S.I., Weidler, P.G., Friedrich, F. and Izvekova, Yu.N., 2016. Properties and Origin of Small Particles in the Atmosphere of Central Asia. Doklady Earth Sciences, 466(2), pp. 177-182. https://doi.org/10.1134/S1028334X16020094

15. Griffin, D.W. and Kellogg, C.A., 2004. Dust Storms and Their Impact on Ocean and Human Health: Dust in Earth's Atmosphere. EcoHealth, 1(3), pp. 284-295. https://doi.org/10.1007/s10393-004-0120-8

16. Koçak, M., Mihalopoulos, N., Tutsak, E., Theodosi, C., Zarmpas, P. and Kalegeri, P., 2015. $P M_{10}$ and $P M_{2.5}$ Composition over the Central Black Sea: Origin and Seasonal Variability. Environmental Science and Pollution Research, 22(22), pp. 18076-18092. https://doi.org/10.1007/s11356-015-4928-2

17. Middleton, N. and Kang, U., 2017. Sand and Dust Storms: Impact Mitigation. Sustainability, 9(6), 1053. https://doi.org/10.3390/su9061053

18. Varenik, A.V., Bobrova, S.A., Katunina, E.V., Malchenko, Yu.A. and Pereverzev, O.A., 2016. Regional Characteristics of Nutrients, Pollutants and Radionuclides Deposition with Atmospheric Precipitations and Aerosols in Sevastopol and Crimean Region. In: SOI, 2016. Proceedings of the State Oceanographic Institute. Issue 217, pp. 209-221 (in Russian).

19. Dyakov, N.N., Malchenko, Yu.A., Bobrova, S.A., Ryabinin, A.I., Lipchenko, A.E. and Taranov, V.V., 2017. Using the Meter Small-Angle Dispersity in Automated Systems Continuous Monitoring Particle Size Distribution of Aerosols. Monitoring Systems of Environment, (1), pp. 24-30. doi:10.33075/2220-5861-2017-1-24-30 (in Russian).

20. Suetin, V.S., Korolev, S.N. and Kucheryaviy, A.A., 2016. Sun Glint Manifestation at Evaluating the Black Sea Water Optical Parameters Using Satellite Measurements. Physical Oceanography, (3), pp. 47-56. doi:10.22449/1573-160X-2016-3-47-56

21. Mielonen, T., Arola, A., Komppula, M., Kukkonen, J., Koskinen, J., de Leeuw, G. and Lehtinen, K.E.J., 2009. Comparison of CALIOP Level 2 Aerosol Subtypes to Aerosol Types Derived from AERONET Inversion Data. Geophysical Research Letters, 36(18), L18804. https://doi.org/10.1029/2009GL039609

22. Vaughan, M.A., Powell, K.A., Winker, D.M., Hostetler, C.A., Kuehn, R.E., Hunt, W.H., Getzewich, B.J., Young, S.A., Liu, Z. and McGill, M.J., 2009. Fully Automated Detection of Cloud and Aerosol Layers in the CALIPSO Lidar Measurements. Journal of Atmospheric and Oceanic Technology, 26(10), pp. 2034-2050. https://doi.org/10.1175/2009JTECHA1228.1 
About the authors:

Alla V. Varenik, Senior Scientist, Marine Hydrophysical Institute of RAS (2 Kapitanskaya St., Sevastopol, 299011, Russia), Ph. D. (Geogr.), SPIN-код: 3277-7914, ORCID ID: 00000001-5033-4576, ResearcherID: H-1880-2014, alla.varenik@mhi-ras.ru

Darya V. Kalinskaya, Junior Scientist, Marine Hydrophysical Institute of RAS (2 Kapitanskaya St., Sevastopol, 299011, Russia), Scopus Author ID: 56380591500, kalinskaya@mhi-ras.ru

Maria A. Myslina, Junior Scientist, Marine Hydrophysical Institute of RAS (2 Kapitanskaya St., Sevastopol, 299011, Russia), 569455@mail.ru

Contribution of the co-authors:

Alla V. Varenik - scientific supervision of research, pitching of the paper idea, selection and analysis of literature, processing and analysis of the data, interpretation of the results obtained, preparation of the paper text, creation of drawings, chemical analysis of the atmospheric precipitations samples

Darya V. Kalinskaya - 7-day back-trajectories analyses using the model of the international network AERONET and the HYSPLIT model, creation of drawings

Maria A. Myslina - the mass PM2.5 and PM10 concentration measuring, editing references

All the authors have read and approved the final manuscript.

The authors declare that they have no conflict of interest. 